\title{
A Prehospital Acute Coronary Syndrome in a Cocaine User: An Unstable Clinical Situation
}

\author{
Nicolas Franchitto • Claudine Cabot • Nicolas Dumonteil • \\ Vincent Bounes • Atul Pathak • Daniel Rougé
}

Published online: 8 February 2011

(C) American College of Medical Toxicology 2011

\begin{abstract}
Chest pain is a common reason why cocaineaddicted patients call the emergency department, and acute coronary syndromes are difficult to diagnose in these situations. A 30-year-old cocaine-user patient contacts the Emergency Medical Assistance Service with constrictive chest pain. A doctor is sent out to the patient at home. The initial ECG is normal. No other aetiology of chest pain is revealed, except nicotine and cocaine addictions. First, a coronary artery spasm is suggested, caused by the injection of cocaine. During the journey, the patient indicates that the chest pain has returned. A 12-lead ECG shows repolarisation abnormality in the form of a subepicardial ischaemia.
\end{abstract}

N. Franchitto $\cdot$ V. Bounes

Pôle de Médecine d'Urgence,

Centre Hospitalier Universitaire Purpan,

Place du Dr-Baylac,

Toulouse Cedex 9, France

N. Franchitto $(\bowtie) \cdot D$. Rougé

Service de Médecine Légale,

Centre Hospitalier Universitaire Rangueil,

Avenue Jean Poulhès,

Toulouse Cedex 9, France

e-mail: franchitto.n@chu-toulouse.fr

C. Cabot

Centre Anti-Poison et de Toxicovigilance Midi-Pyrénées,

Centre Hospitalier Universitaire Purpan,

Place du Dr-Baylac,

Toulouse Cedex 9, France

N. Dumonteil

Service de Cardiologie,

Centre Hospitalier Universitaire Rangueil,

Avenue Jean Poulhès,

Toulouse Cedex 9, France

\section{A. Pathak}

Service de Pharmacologie Clinique,

Centre Hospitalier Universitaire Rangueil,

Avenue Jean Poulhès,

Toulouse Cedex 9, France
Fibrinolysis is not prescribed in view of the patient's history and of the proximity of the interventional cardiology team. The coronary angiogram enables the diagnosis of myocardial bridging in the middle anterior interventricular artery, and no significant lesion of the coronary arteries is noted. A particular feature of prehospital management in France is that medical care can be given in the early stages by a physician who is called by the patient. This case report discusses the specific care requirements of which the emergency physician needs to be aware in the context of this unstable clinical situation due to the urgency associated with the difficulties of ECG diagnosis of ST-segment elevation in cocaine users.

Keywords Cocaine $\cdot$ Prehospital care $\cdot$ Coronary vasospasm - Fibrinolytic agents - Interventional cardiology · Delay of care

\section{Case Presentation}

A 30-year-old patient contacted the Emergency Medical Assistance Service and described constrictive chest pain, of less than 5 min duration, occurring between the breasts, without radiation. He last took cocaine $2 \mathrm{~h}$ previously. Upon the arrival of the emergency medical team, $12 \mathrm{~min}$ later, the clinical examination revealed a blood pressure of $175 / 98 \mathrm{mmHg}$, symmetrical in both arms, heart rate of $68 /$ min, regular, all peripheral pulses were palpable, calves were supple, and there were no clinical signs of complete cardiac failure nor of poor tolerance of hypertension. A biological assessment carried out 3 months previously showed no dyslipaemia, no family history of coronary disease, and no diabetes. The patient had no previous ECG. A peripheral intravenous line was inserted, and isosorbate dinitrate at a titrated dose of $0.5 \mathrm{mg} / \mathrm{h}$ was prescribed for both its protective effect against recurrent spasms and also to control reactive arterial hypertension. The patient was 
transferred under medical supervision to the hospital, located approximately 40 min away from the patient's home. About $25 \mathrm{~min}$ after leaving his home, the patient indicated that the chest pain had returned. An ECG was taken (Fig. 1). Blood pressure was 138/66 mmHg. The treatment was completed with $250 \mathrm{mg}$ of intravenous aspirin and a subcutaneous lowmolecular-weight heparin, enoxaprin, at $1 \mathrm{mg} / \mathrm{kg}$. Fibrinolysis was not prescribed in view of the patient's history and of the proximity of the interventional cardiology team to carry out invasive exploration using coronary angiography. On arrival at the hospital, the patient was transferred to the cardiology department, and a coronary angiogram was performed (Fig. 2).

Question: What is the patient suffering from and what explanation for the cause would you consider?

Answer: A cocaine-induced coronary vasospasm associated with a silent myocardial bridging

\section{Discussion}

Emergency departments handle patients presenting with chest pain related to cocaine-addicted patients on a frequent basis. However, although the procedures to be followed for coronary syndrome with or without ST-segment elevation are encoded in the guidelines published by the American Heart Association and the European Society of Cardiology, there are specific care requirements for treating chest pain in patients who use cocaine [1]. On the pathophysiological level, cocaine provides both $\alpha$ and $\beta$ receptor stimulations and has also been associated with coronary artery spasm, further mediated by the direct action of cocaine on vascular smooth muscle [2]. The formation of an arterial thrombus may be caused by cocaine, both through direct activation of platelets and indirect activation by increasing platelet aggregation mediated by $\alpha$-adrenergic activity but also by the fact that adenosine diphosphate-induced platelet aggregation is enhanced, and tissue plasminogen activator inhibitor is increased in this situation [3]. The incidence of myocardial infarction is very low, estimated at around $5 \%$ to $6 \%$ [4]. The patient is usually a young, male smoker presenting no other risk factors for heart disease, with a history of recurrent chest pain [4], which is the most frequent complaint, at around $56 \%$. In this situation, an ECG is abnormal in $56-84 \%$ of patients, with cocaineassociated chest pain [5]. The change in the ECG reading during transportation, despite the intravenous dose of nitroglycerin, which has been shown to alleviate cocaineinduced coronary vasoconstriction [6], leads to another difficulty for the doctor accompanying the patient, in terms of selecting the further treatment to be administered in view of the changing clinical condition. No randomized, placebo-controlled trials regarding therapies to improve outcomes of patients sustaining a cocaine-associated myocardial infarction have been reported [5]. In our case study, low-molecular-weight heparin and aspirin were adminis-

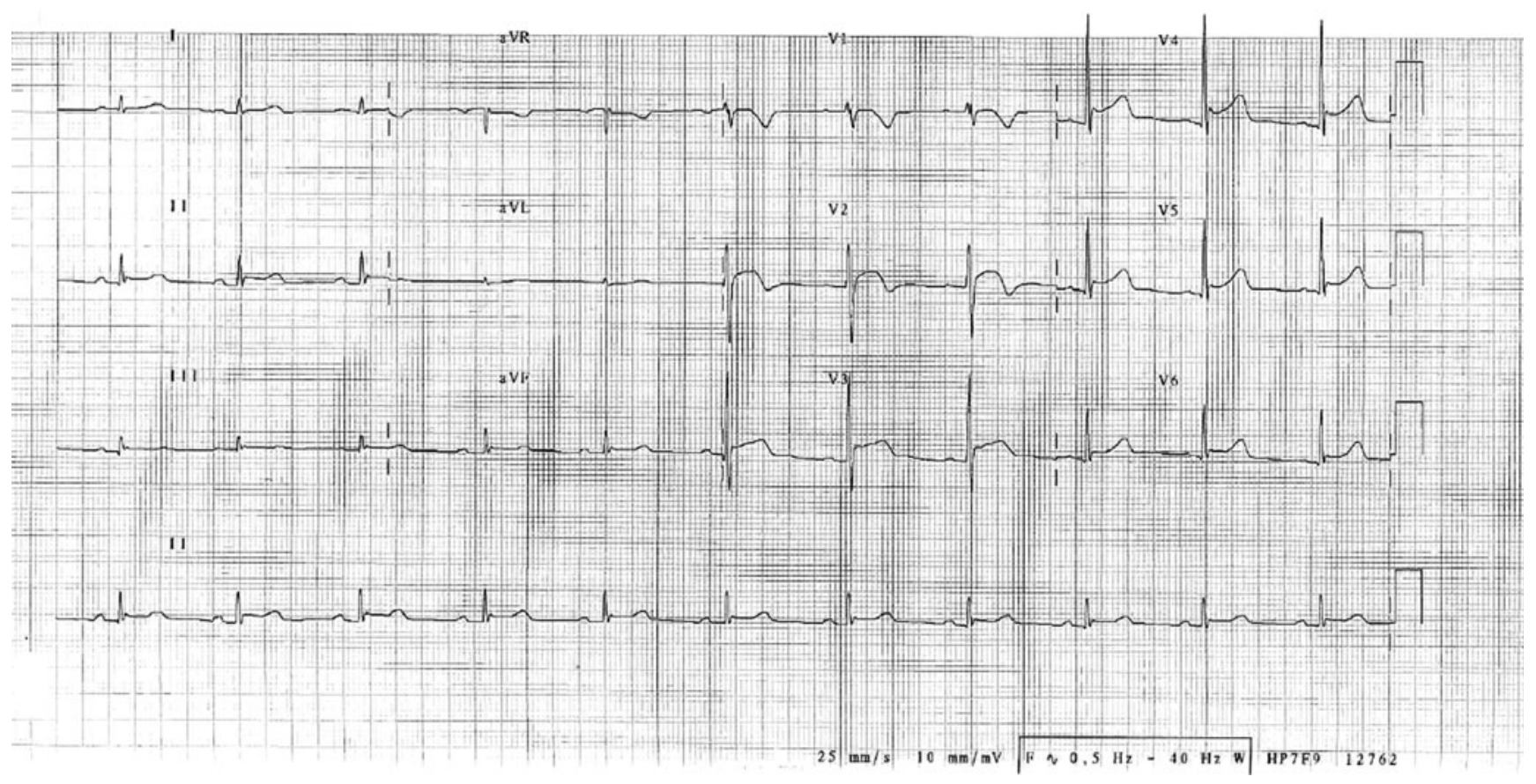

Fig. 1 ECG showed a regular sinus rhythm of $70 / \mathrm{min}$, with no rhythmic or auricular-ventricular conduction anomalies, a normal QRS axis, a discrete incomplete right branch block associated with repolarisation abnormality in the form of a subepicardial ischemic wave in V1 and anomalies atypical of repolarisation in the entire precordium, in view of the J-point and ST-segment elevation, with upward convexity in V2 and V3 and upward concavity in V4 to V6 

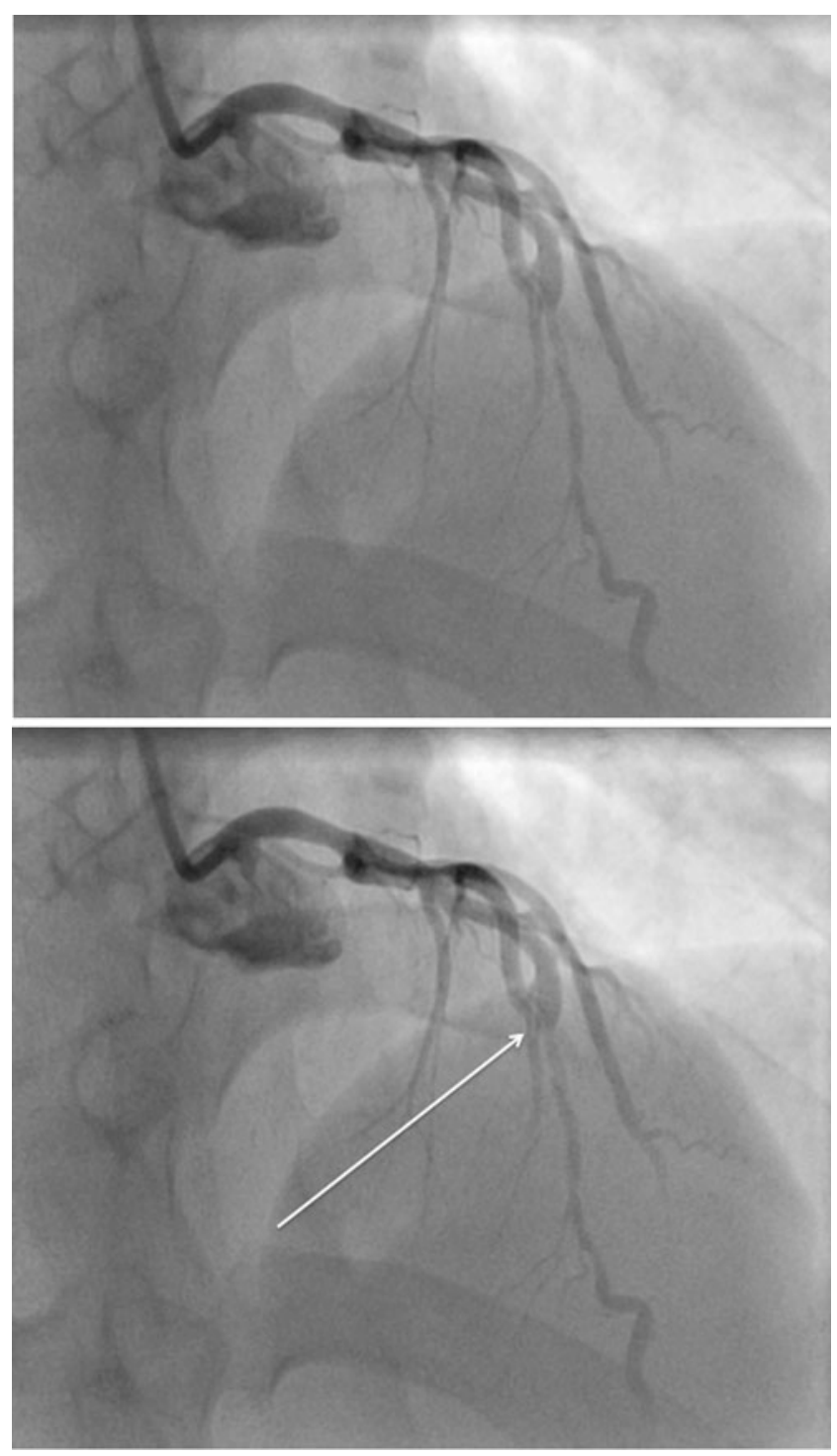

Fig. 2 Myocardial bridging in the middle anterior interventricular artery, nor valve disease, and the ejection fraction of the left ventricle is at $70 \%$ tered in accordance with the guidelines. However, we could argue that failure to take action on ST elevation was below the standard of care for patients with chest pain, but thrombolysis has been refuted on the grounds of the rare incidence of myocardial infarction as well as the risk of the potential complications in this situation [3]. Verapamil is chosen in myocardial bridging for its effect against coronary artery spasm, and its ability to reverse cocaineinduced arterial vasoconstriction has been shown in cardiac catheterization studies [7].

Conflict of Interest The authors have no potential financial conflicts of interest to report.

\section{References}

1. Antman EM, Anbe DT, Armstrong PW et al (2004) ACC/AHA guidelines for the management of patients with ST-elevation myocardial infarction: executive summary: a report of the ACC/ AHA Task Force on Practice Guidelines (Writing Committee to Revise the 1999 Guidelines for the Management of Patients with Acute Myocardial Infarction). Circulation 110:588-636

2. Dattilo PB, Hailpern SM, Fearon K et al (2008) B-blockers are associated with reduced risk of myocardial infarction after cocaine use. Ann Emerg Med 51:117-125

3. Hollander JE, Henry TD (2006) Evaluation and management of the patient who has cocaine-induced chest pain. Cardiol Clin 24:103-114

4. Hoffman RS (2008) Cocaine and $\beta$-blockers: should the controversy continue? Ann Emerg Med 51:127-129

5. McCord J, Jneid H, Hollander JE et al (2008) Management of cocaineassociated chest pain and myocardial infarction: a scientific statement from the American Heart Association Acute Cardiac Care Committee of the Council on Clinical Cardiology. Circulation 117:1897-1907

6. Brogan WC 3rd, Lange RA, Kim AS et al (1991) Alleviation of cocaine-induced coronary vasoconstriction by nitroglycerin. J Am Coll Cardiol 18:581-586

7. Negus BH, Willard JE, Hillis LD et al (1994) Alleviation of cocaine-induced coronary vasoconstriction with intravenous verapamil. Am J Cardiol 73:510-513 